\title{
Análise da estrutura de Lc 2,22-39 e a utilização das Escrituras Veterotestamentárias em sua moldura literária (vv.22-24.39)
}

\author{
Analysis of the structure of Luke 2, 22-39 \\ and the utilization of the veterotestamentary \\ Scriptures in its literary frame (vv.22-24.39)
}

Boris Agustín Nef Ulloa

\section{Resumo}

A perícope lucana da "Apresentação de Jesus no Templo" (2,22-39) possui uma moldura literária (vv.22-24.39), a qual é de fundamental importância para compreender o sentido teológico e a relação entre as duas subunidades (vv.25-35 e vv.36-38) que compõem o centro do relato. Por meio da análise da estrutura do conjunto da perícope nota-se o paralelismo literário presente nos vv.22-24.39 e destaca-se como o autor lucano utiliza os textos veterotestamentários ( $\operatorname{Lv}$ 12,4-6: quanto à prescrição sobre a purificação da mãe após o parto; e Ex 13,2.12.13b.15b: quanto ao resgate dos primogênitos) para a composição da moldura. Por outro lado, com a identificação do centro literário da moldura (v.23c) nota-se como este aponta para o sentido teológico-cristológico (identidade e missão do menino) das duas subunidades que compõem a narrativa lucana da "Apresentação de Jesus no Templo".

Palavras-chave: Apresentação de Jesus no Templo; Moldura literária; Uso das Escrituras em Lucas. 


\begin{abstract}
The Lucan pericope of the "Presentation of Jesus at the Temple" (2,22-39) shows a literary frame (vv.22-24.39), which has a fundamental importance for one's understanding of the theological meaning and the relationship between the two subunities (vv.25-35 e vv.36-38) that form the centre of the narrative. By means of analysing the structure of the whole of the periscope one can notice the literary parallelism that exists in this vv.22-24.39 and the way in which Luke makes use of the veterotestamentary texts ( $\operatorname{Lv} 12,4-6$ : about the prescription with regard to the mother's purification after giving birth; Ex 13,2.12.13b and 15b: with regard to the retrieval of the eldest sons) for the composition of the frame. On the other hand, with the identification of the literary centre of the frame (v.23) one notices how it points towards the Theological-Christological (meaning the boy's identity and mission) of the two subunities that make up the Lucan narrative of the "Presentation of Jesus at The Temple".
\end{abstract}

Keywords: The Presentation of Jesus at the Temple; Literary Frame; Use of Scriptures in Luke.

\title{
Introdução
}

A narrativa da "Apresentação de Jesus no Templo" (Lc 2,22-39) ${ }^{1}$ se desenvolve em um tempo e em um lugar precisamente descritos, ao interno de um

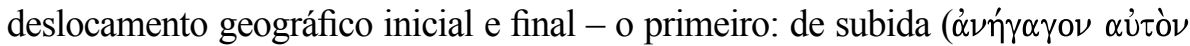

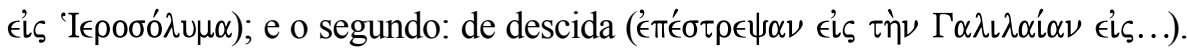
Esta perícope possui uma moldura literária (vv.22-24.39), a qual é de fundamental importância para compreender o sentido teológico e a relação entre as duas subunidades (vv.25-35 e vv.36-38) que compõem o centro do relato.

Por meio da análise da estrutura do conjunto da perícope nota-se o paralelismo literário presente nos vv.22-24.39 e destaca-se como o autor lucano utiliza os textos veterotestamentários (Lv 12,4-6: quanto à prescrição sobre a purificação da mãe após o parto; e Ex 13,2.12.13b.15b: quanto ao resgate dos primogênitos) para a composição da moldura. De fato, a insistência de que

\footnotetext{
${ }^{1}$ Este artigo analisa de forma sintética e pontual a questão proposta. Para quem deseja aprofundar o estudo da perícope canônica sugere-se a obra exegético-teológica de minha autoria: “A Apresentação de Jesus no Templo. (Lc 2,22-39). O testemunho profético de Simeão e Ana como ícone da história da Salvação”. São Paulo: Paulinas 2012 (Coleção Exegese).
} 
tudo é realizado segundo a Lei é fundamental para visualizar o paralelismo existente ao interno da inclusão (inicial + final).

Por outro lado, com a identificação do centro literário da moldura (v.23c) nota-se como este aponta para o sentido teológico-cristológico (identidade e missão do menino) das duas subunidades que compõem esta narrativa lucana.

\section{A inclusão (vv.22-24.39)}

A perícope apresenta uma inclusão (vv.22-24.39) que corrobora sua unidade $^{2}$. Esta é formada por dois elementos: a fórmula $\left[\nu \text { ó } \mu \varsigma_{\varsigma}+\text { genitivo }\right]^{3} \mathrm{e}$ o deslocamento geográfico-espacial ${ }^{4}$.

A delimitação inicial (v.22) contém dois elementos significativos: uma

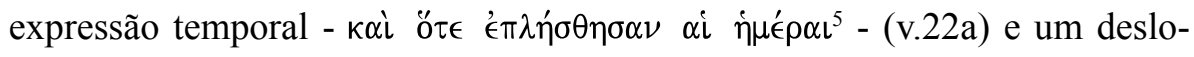

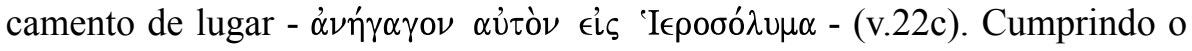

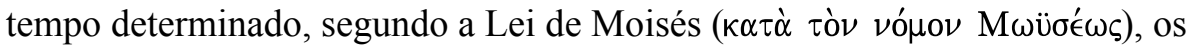
pais do menino sobem a Jerusalém com duas finalidades explícitas: apresentar o menino primogênito ao Senhor (v.22d) e oferecer um sacrifício (v.24a).

A delimitação final é assinalada por três elementos correlacionados

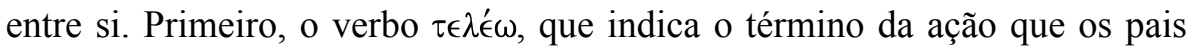
haviam iniciado nos vv.22-24. Segundo, tal ação é realizada segundo a Lei

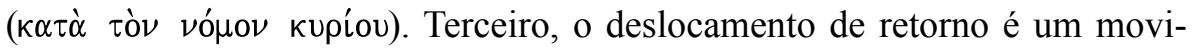
mento em sentido inverso ao inicial, de Jerusalém até Nazaré na Galileia ${ }^{6}$.

\footnotetext{
${ }^{2}$ F. Bovon, El Evangelio según san Lucas, I, 197; W. RAdL, Der Ursprung Jesu, Traditionsgeschichtliche Untersuchungen zu Lukas 1-2, Freiburg: Herder, 1996, 210; J. M. LóPez Mauleón, Tò

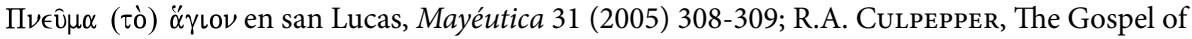
Luke, in L.E. Keск (Ed.), The New Interpreter's Bible, IX, Nashville: Abingdon Press, 1996, 73.

${ }^{3}$ Essa aparece 3x na inclusão inicial (vv.22b.23a.24b) e 1x na final (v.39b).

${ }^{4}$ Movimento que está composto pela subida até Jerusalém, a permanência no Templo (onde se desenvolvem os encontros com Simeão e Ana) e a descida até Nazaré na Galileia. Segundo A. VALENTINI, La rivelazione di Gesù dodicenne al Tempio (Lc 2,41-52). Estudios Bíblicos 50 (1992), 266, esta estrutura da inclusão é uma forma de estribilho tipicamente lucano que é frequente nas narrativas da infância.

${ }^{5}$ Essa expressão temporal, com pequenas variações, aparece outras $3 \mathrm{x}$ nos relatos lucanos da infância $(1,23 ; 2,6.21)$. Segundo R. Bultmann, The History of the Synoptic Tradition, Oxford: Blackwell, 1963, 359, o evangelista Lucas, com frequência, utiliza expressões temporais para conectar uma cena com aquela que a precede.

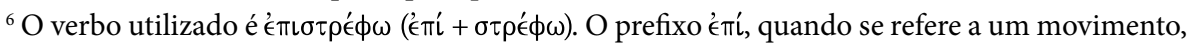
descreve um sentido que parte do alto, a partir de um lugar elevado ou superior até um lugar mais baixo. Esse movimento é justamente oposto ao indicado pelo prefixo verbal $\alpha \nu \alpha$ (de baixo para cima, de baixo para o alto) que é empregado no v.22.
} 
Estes elementos, igual que no v.22, integram duas preposições com verbos no indicativo aoristo terceira pessoa do plural ( $\epsilon^{\prime} \epsilon^{\prime} \lambda \epsilon \sigma \alpha \nu$ e $\left.\epsilon^{\prime} \epsilon \pi^{\prime} \epsilon \sigma \tau \rho \epsilon \psi \alpha \nu\right)$. O paralelismo entre os modos e tempos verbais dos vv.22.39 reforça a ideia de uma inclusão para todo o conjunto da perícope.

A perfeita continuidade entre os vv.22-24.39 nos leva a suspeitar que eles constituam originariamente uma sequência. De fato, ao analisar os vv.22-24.39, se observa que estão formados por treze segmentos no total, dentre os quais, 12 segmentos são paralelos dois a dois e o décimo terceiro é central.

\begin{tabular}{|c|c|c|}
\hline 2 & 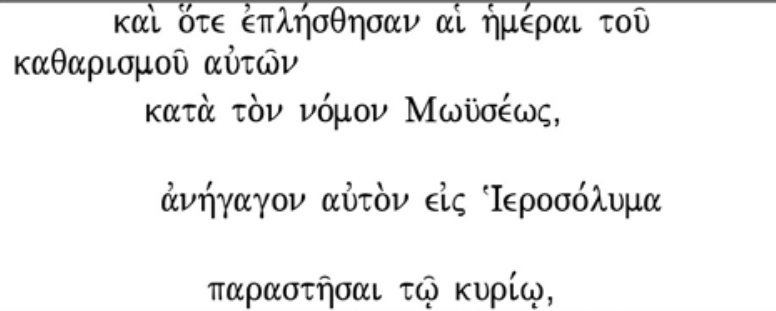 & $\begin{array}{l}\text { B } \\
\text { C }\end{array}$ \\
\hline 3 & 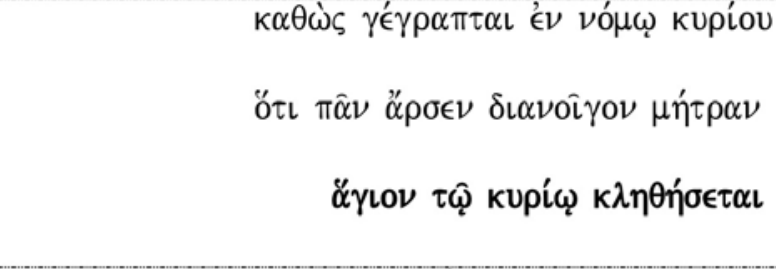 & $\begin{array}{l}\mathbf{E} \\
\mathbf{F} \\
\mathbf{G}\end{array}$ \\
\hline 4 & 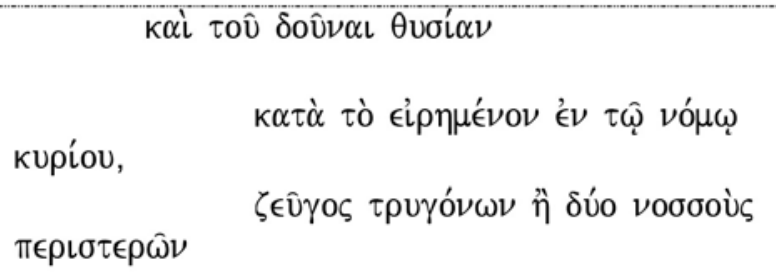 & $\begin{array}{l}\mathbf{E}^{1} \\
\mathbf{F}^{1}\end{array}$ \\
\hline 9 & 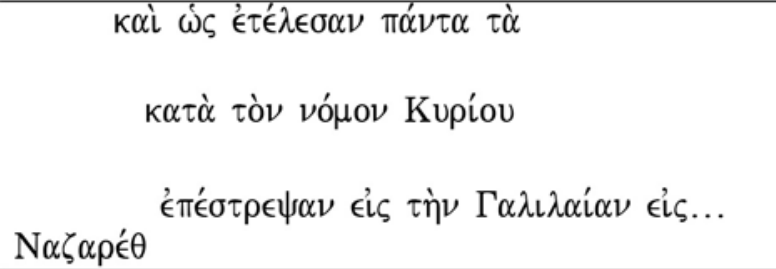 & $\begin{array}{l}A^{1} \\
B^{1} \\
C^{1}\end{array}$ \\
\hline
\end{tabular}

Note-se que os segmentos $\mathrm{A}-\mathrm{A}^{1}$ começam com uma conjunção subordinada temporal; de modo particular, em A é assinalado que se cumpriu um tempo determinado, o tempo da $\kappa \alpha \theta \alpha \rho\left\llcorner\sigma \mu o ́ s . ~ O s ~ s e g m e n t o s ~ B-B^{1}\right.$ colocam em paralelo

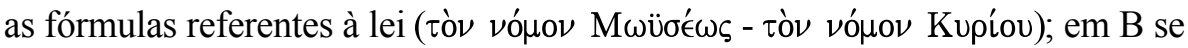


afirma que o tempo da $\kappa \alpha \theta \alpha \rho \iota \sigma \mu o ́ s$ é determinado pela Lei de Moisés; em $\mathrm{B}^{1}$ se declara que os pais realizaram tudo segundo a lei do Senhor. Em C-C ${ }^{1}$, os dois verbos em indicativo aoristo ( $\alpha \nu \eta ́ \gamma \alpha \gamma o \nu$ e $\epsilon \pi \epsilon ́ \sigma \tau \rho \epsilon \psi \alpha \nu)$ expressam deslocamento;

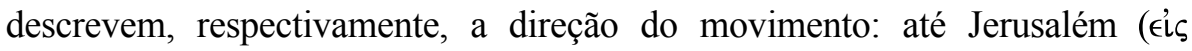

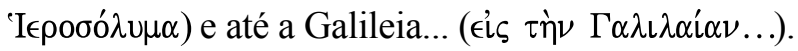

Os segmentos D-D ${ }^{1}$ conduzem ao centro da inclusão e têm duas funções; a primeira é temática: assinalam os dois objetivos da subida a Jerusalém: apresentá-lo ao Senhor (D) e oferecer um sacrifício $\left(\mathrm{D}^{1}\right)$; a segunda é estrutural, sustenta o paralelismo interno do relato que está presente nos segmentos $\mathrm{E}$, $\mathrm{E}^{1}, \mathrm{~F}, \mathrm{~F}^{1}$, os quais, por sua vez, sustentam o segmento central G. Em E-E $\mathrm{E}^{1}$ se

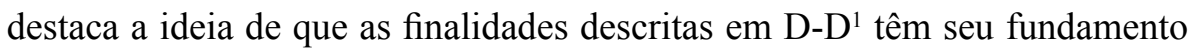
na Lei do Senhor. Ao centro, o recurso explícito das Escrituras aparece nos segmentos $\mathrm{F}, \mathrm{F}^{1}$ e $\mathrm{G}$.

\section{A referência às Escrituras}

Antes de tudo, é importante observar que em nenhum lugar da tradição religiosa de Israel se exigia que o resgate do primogênito se realizasse no Templo e muito menos se requeria a presença do menino para o cumprimento do preceito ${ }^{7}$. Quanto à purificação da mãe, a Lei mencionava o costume de ir ao santuário ${ }^{8}$, mas não exigia sua presença e tampouco a do filho ${ }^{9}$. $\mathrm{Na}$ realidade, os pais do primogênito eram livres para cumprir estes preceitos onde lhes parecesse melhor.

No entanto, esta não obrigatoriedade de ir a Jerusalém serve a Lucas como um motivo para indicar que os pais do menino não somente eram observantes da lei, senão que também piedosos frente à sacralidade do Templo e da cidade de Jerusalém. Este comportamento fica melhor demonstrado quando se observa Ne 10,37, onde se afirma que a ação de levar ( $\phi$ é $\rho \omega)$ os primogênitos

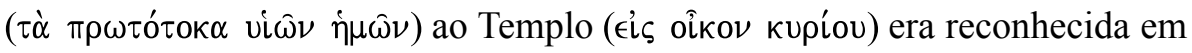
Israel como um sinal de especial devoção e fidelidade à Lei. De fato, se pode observar que o perfil dos pais de Jesus não é o de simples observantes dos

\footnotetext{
${ }^{7}$ M.-J. Lagrange, Évangile selon saint Luc, Paris: Lecoffre, 1921, 81; S. Muñoz Iglesias, Los Evangelios de la infancia, III, Madrid: Editorial Católica, 1987, 164.

${ }^{8}$ Segundo H. L. Strack; P. Billerbeck, Kommentar zum Neuen Testament aus Talmud und Midrasch, II, München: Beck, 1924, 119-120, nos tempos do NT esse rito tinha lugar na porta de Nicanor, entrada oriental do pátio das mulheres.

${ }^{9}$ F. Bovon, El Evangelio según san Lucas, I, 203.
} 
preceitos religiosos; a intenção do evangelista é apresentá-los como extremamente fiéis e devotos à Lei ${ }^{10}$.

Frente a esta realidade sobre os costumes religiosos da família judaica surgem inevitavelmente algumas questões: Por que e com qual objetivo o evangelista teria optado explicitamente por relatar o deslocamento geográficoespacial dos pais com seu primogênito? Os dois preceitos que, ordinariamente, são independentes entre si, teriam sido colocados lado a lado como um recurso literário para chegar ao objetivo principal que é descrever a manifestação do menino no Templo?

Um aspecto é evidente, o autor se vale de duas importantes exigências prescritas na Lei para favorecer o deslocamento ascendente (geográficoteológico) dos pais com seu filho até o Templo de Jerusalém, lugar onde se revela a identidade do menino e as consequências de sua missão ${ }^{11}$.

A seguir, se apresenta um estudo sobre as referências da lei citadas nos vv.22a.23b.c.24c, quanto à purificação da parturiente $(\operatorname{Lv} 12,1-8)$ e à consagração-resgate dos primogênitos (Ex 13,1-2.11-16). Essas referências não correspondem literalmente à $\mathrm{LXX}^{12}$. Assim, se confirma a afirmação de Schürmann: na realidade, ninguém sabe com segurança qual(ais) era $(\mathrm{m}) \mathrm{o}(\mathrm{s})$ texto(s) grego(s) das Escrituras que o autor teve à disposição ${ }^{13}$.

\footnotetext{
${ }^{10}$ M. Coleridge, Nueva lectura de la infancia de Jesús, Nueva lectura de la infancia de Jesús. La narrativa como cristología en Lucas 1-2, Córdoba: El Almendro, 2000, 163.188. Segundo A. Simón Muñoz, El Mesías y la hija de Sión. Teologia de la redención en Lc 2,29-35, Madrid: Ciudad Nueva, 1994, 57, não há dúvida de que Maria e José são descritos como fiéis cumpridores da lei de Deus, penetrados da piedade mais autêntica de Israel; Segundo R.E. Brown - K. P. Donfried - J. A. Fitzmyer - J. Reumann, María en el Nuevo Testamento, Salamanca: Sígueme, $2002^{4}, 156-157$, a obediência de Maria e José já havia sido ilustrada na narrativa da circuncisão do menino e imposição do nome ao oitavo dia (cf. 2, 21). Essa é confirmada na perícope sucessiva (cf. 2, 41-52), onde os pais obedecem a prática cultural subindo a Jerusalém para celebrar a festa anual da Páscoa.

${ }^{11}$ S. Muñoz Iglesias, Los evangelios de la infancia, I, Madrid: Editorial Católica, 1990², 294.

${ }^{12}$ K. J. Thомаs, Torah Citations in the Synoptics. New Testament Studies 24 (1977), 91.

${ }^{13}$ H. SCHÜRMANN, Il vangelo di Luca, I, Brescia: Paideia, 1983, 277-278.
} 


\subsection{Quanto à purificação da mãe}

Os preceitos sobre as parturientes se encontram no Lv 12,1-814. Os vv.4.6.8. são aqueles que mais diretamente se relacionam com o texto lucano. Quando os vv.4.6. são analisados em paralelo a Lc 2,22a, observa-se uma expressão temporal, com a qual se faz referência a um cumprimento de tempo que está presente nos três versículos. No v.4 é utilizado o verbo $\pi \lambda \eta \rho o ́ \omega ;$ no v.6 a ideia é assinalada por $\dot{\alpha} \nu \alpha \pi \lambda \eta \rho o ́ \omega ;$; enquanto que em 2,22a se emprega $\pi^{\prime}\left\langle\mu \pi \lambda \eta \mu \iota^{15}\right.$.

Note-se que o texto lucano começa com um fato já consumado. Esta ideia é assinalada pelo verbo $\pi i \mu \pi \lambda \eta \mu \iota$ no indicativo aoristo: "quando se cumpriram os dias", enquanto que, em Lv 12,4.6, os verbos estão no subjuntivo aoristo. Além disso, segundo v.4, depois da circuncisão do filho, a mãe devia cumprir trinta e três dias de purificação. Neste período ela estava impedida de entrar em qualquer lugar santo. Lucas afirma explicitamente que esse tempo de purificação já se cumpriu. Logo que este obstáculo legal de acesso ao santuário fora removido, o evangelista pode deslocar os pais, afirmando que fizeram subir o menino a Jerusalém (v.22a) e o fizeram entrar no Templo (v.27b).

O estudo paralelo destes versículos revela duas significativas diferenças.

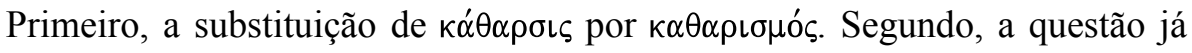
levantada na crítica textual sobre o pronome genitivo plural $\alpha \dot{v} \tau \hat{\omega} \nu^{16}$.

\footnotetext{
${ }^{14}$ No v.2 determina-se o tempo de impureza quando nasce um varão; no v.3 estabelece-se que a circuncisão deve ser realizada no oitavo dia; no v.4, as mães são proibidas de tocar objetos sagrados e de entrar nos lugares sagrados até que se completassem os dias da purificação, isto é, os trinta e três dias posteriores à circuncisão do filho; o v.5 refere-se ao tempo de purificação quando nascia uma menina; o v.6 especifica o que deve ser levado ao sacerdote (um cordeiro para o holocausto e uma pomba para o sacrifício expiatório); o v.7 estabelece que é o sacerdote quem deve oferecer o sacrifício ao Senhor; o v.8 dá a possibilidade, aos que não tem meios para comprar um cordeiro, de oferecer em seu lugar duas pombas, um para o holocausto e outro para o sacrifício expiatório. Note-se, sem dúvida, Lv 12,1-3 é utilizado com substrato nos dois textos lucanos $(1,59 ; 2,21)$.

${ }^{15} \mathrm{O}$ verbo $\pi i \mu \pi \lambda \eta \mu \iota$ é muito importante no texto lucano. Note-se que em todo o NT aparece $24 \mathrm{x}$, das quais $22 \mathrm{x}$ se encontra na obra lucana (13x em Lc; 9x em At). Em Lc 1-2, $\pi i ́ \mu \pi \lambda \eta \mu \iota$ é utilizado $8 \mathrm{x}(1,15.23 .41 .57 .67 ; 2,6.21 .22)$.

${ }^{16}$ Segundo W. BAUER; W.F. ARNDT; F.W. GINGRICH; F. W. DANKER, (Eds). A Greek-English Lexicon of the New Testament and Other Early Christian Literature, Chicago: Chicago University Press / London: Williams and Norgate, 1979, 387, com o pronome no plural, o autor estaria incluindo José na purificação: "talvez seja um uso coloquial para relatar a presença de José no processo". R. LAUrentin, I vangeli dell'infanzia di Cristo. La verità del natale al di là dei miti, Milano: Paoline, 1986, 102-104, admite que $\alpha$ ù $\omega \hat{\nu}$ poderia em princípio referir-se a José e Maria já que José está envolvido na viagem para Jerusalém; mas, ao mesmo tempo, assinala que a purificação se referia ao sangue da mãe, motivo que não permite inclui-lo nesse pronome. Segundo M. PÉREZ
} 
Quanto à primeira questão note-se que os termos $\kappa \alpha \theta \alpha \rho \iota \sigma \mu o ́ \varsigma$ e $\kappa \alpha ́ \theta \alpha \rho \sigma \iota \varsigma$

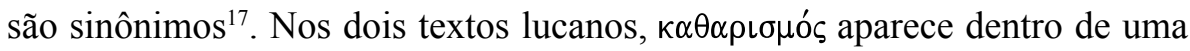
estrutura semelhante, cujo sentido é análogo. Em 5,14 se refere à purificação legal de um leproso, onde Jesus, depois de curá-lo, lhe diz que se mostre ao sacerdote e lhe leve a oferenda, segundo ordena a lei de Moisés. Nas duas ocasiões, $\kappa \alpha \theta \alpha \rho \iota \sigma \mu o ́ \varsigma$ está associado à figura de Moisés, onde é recordado como o legislador, como aquele que recebeu da parte do Senhor os preceitos que deveriam ser observados pelo povo da aliança. Note-se que os dois ritos de purificação são definidos "segundo a lei de Moisés" $(2,22)^{18}$ e "segundo ordenou Moisés" $(5,14)^{19}$.

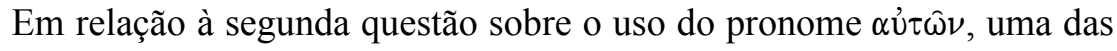
explicações plausíveis é oferecida pelos autores que defendem um original hebraico para Lc 1-2. Segundo García Pérez-Herranz Marco, a explicação "é

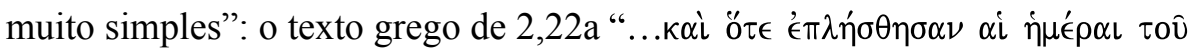
$\kappa \alpha \theta \alpha \rho\llcorner\sigma \mu о \hat{~} \alpha u ̛ \tau \hat{\nu} \nu$ " revela como fundo um clássico exemplo hebraico, onde se utiliza o sufixo pessoal com valor de artigo, como ocorre também em Gn 34,24; desse modo, o texto grego oferece uma tradução servil, sem tomar em conta o sentido original do texto hebraico ${ }^{20}$.

Fernández, Tradiciones Mesiánicas en el Targum Palestinense, Valencia: Artes Gráficas Soler, 1981, 97-101, o Tg PsJ de Gn 49,1 se distingue de seus paralelos no Tg Neofiti e Tg Palestinense ao acrescentar que, quando Jacó chamou seus filhos a reunir-se em torno dele para revelar-lhes os tempos escondidos e os segredos...., eles recebem a exortação de primeiro purificar-se de suas impurezas para que estivessem aptos a receber a revelação. Segundo E. CORTÉS, Los discursos de Adiós de Gn 49 a Jn 13-17. Pistas para la historia de un género literario en la antigua literatura judía, Barcelona: Herder, 1976, 470-481, o tema da purificação pertence ao gênero literário testamental. O autor identifica a purificação como uma condição prévia e necessária para a revelação que virá em seguida.

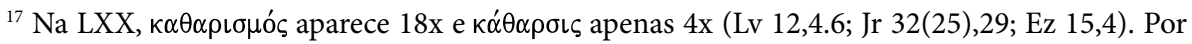

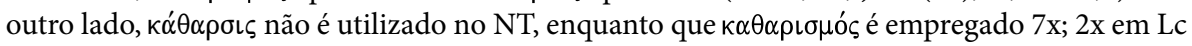
$(2,22 ; 5,14$ par. Mc 1,44).

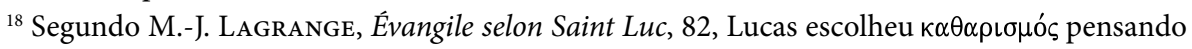

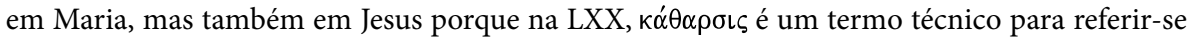
à mulher que deu à luz.

${ }^{19}$ Além disso, em At 21,26, para assinalar outro ato de purificação ritual no Templo, Lucas utiliza o termo $\dot{\alpha} \gamma \nu \iota \mu$ ó $\varsigma$ (da raiz $\dot{\alpha} \gamma \nu \dot{\zeta} \zeta \omega$ ).

${ }^{20}$ J.M. GARCÍA PÉREZ; M. HERRANZ MARCO, La infancia de Jesús según Lucas, Madrid: Ediciones Encuentro, 2000, 88. Por outro lado, S. MUÑOZ IGLESIAS, Los Evangelios de la infancia III, 175-177, partindo da hipótese de um texto hebraico subjacente para Lc 1-2, diz estar de acordo com F.X. ZORREL (Lexicum graecum Novi Testamenti, Paris 19312 ${ }^{2}$, col. 632),

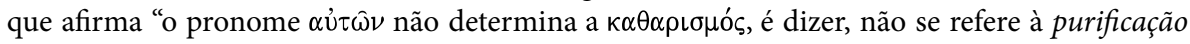
deles (sejam quem forem); na realidade, $\alpha$ ù $\omega \hat{\nu}$ equivaleria a um dativo com o qual se indica os afetados pela expressão temporal"; e ainda sugere: "que $\alpha$ ป $\tau \hat{\omega} \nu$ teria sido um sufixo masculino 
A respeito do tipo de oferenda, no v.6 se observa a presença do verbo

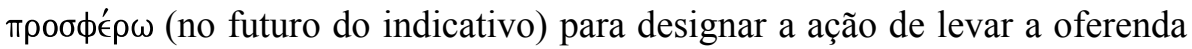
para o sacrifício, mediante a qual o sacerdote declara que a mãe se encontra em estado de pureza legal (vv.7-8). No v.6b se determina o lugar onde a mulher deve levar sua oferenda ao sacerdote: na porta da tenda do encontro ${ }^{21}$. No v.8, se prescreve um sacrifício alternativo para os mais pobres: "o cordeiro e a pomba", podem ser substituídos por "duas pombas ou duas rolas".

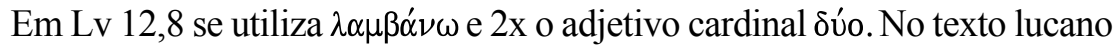
é empregado $\delta i ́ \delta \omega \mu \iota$ com o complemento no acusativo ( $\left.\theta v \sigma^{\prime} \alpha \nu\right)$. Ao descrever o sacrifício, o autor substitui o primeiro adjetivo cardinal por $\zeta \in \hat{y}$ o $\varsigma$ e preserva o segundo como aparece em Lv 5,11. Em Lv 12,8 se afirma que os pobres poderiam apresentar esta oferenda ao sacerdote pela purificação da mãe ${ }^{22}$. A partir do contexto lucano se deduz que o sacrifício apresentado pelos pais de Jesus corresponde exatamente a esta prescrição levítica ${ }^{23}$. Mas note-se que, em Lv 5,7b.11b; $12,8 b$, os textos descrevem a realização de dois sacrifícios; o primeiro é expiatório (pelo pecado da mãe) e o segundo é um holocausto. Lucas omite totalmente esta distinção. $\mathrm{O}$ autor cristão afirma tão somente que os pais sobem a Jerusalém para "oferecer um sacrifício, segundo o dito na lei do Senhor, um par de rolas ou duas pombas" (v.24a.b.c.), sem precisar o tipo de sacrifício realizado. A ideia de um sacrifício de expiação pelo pecado da mãe desaparece por completo ${ }^{24}$.

Frente a este panorama emergem novas perguntas: Por que Lucas não fala de expiação e elimina qualquer referência ao pecado da mãe? Qual é sua intenção ao não tocar este ponto? Por trás destas omissões, se poderia entrever a existência de uma motivação teológica cristã? A resposta mais provável é que Lucas concentra sua narrativa na figura do menino; seu objetivo é a revelação da identidade e missão de Jesus e a figura da mãe é utilizada como instrumento que aponta para o menino.

de terceira pessoa do plural (ה) acrescentado a $\eta^{\prime} \mu \epsilon^{\prime} \rho \alpha \iota$ ou a $\kappa \alpha \theta \alpha \rho\llcorner\sigma \mu o \hat{v}$, mas equivalente, na realidade, a um dativo regido pelo verbo. Assim também em Jr 25,34 e Sf 3,10".

${ }^{21} \mathrm{Na}$ história das instituições religiosas de Israel, a "tenda do encontro" corresponde ao futuro Templo de Jerusalém. Com o desenvolvimento de Jerusalém e sua progressiva centralidade enquanto capital político-religiosa (primeiro do reino unificado e depois do reino de Judá), o Templo foi ocupando um lugar sempre mais destacado. Note-se que, após o retorno do Exílio da Babilônia, o Segundo Templo foi concebido como o lugar central do judaísmo.

${ }^{22}$ J.E. HARTLEY, Leviticus, Word Biblical Commentary 4, Dallas: Word Books, 1992, 170.

${ }^{23}$ R.E. BROWN, El nacimiento del Mesías, 469.

${ }^{24} \mathrm{O}$ texto lucano omite também a ação de um sacerdote. Essa omissão é bastante compreensível já que, segundo M. NOTH, Levítico, Brescia: Paideia, 1989, 124, os sacrifícios no Templo, de acordo com as prescrições da lei, eram reservados exclusivamente aos sacerdotes. 


\subsection{Quanto ao resgate dos primogênitos ${ }^{25}$}

O preceito referente aos primogênitos se encontra em Ex 13,2.12.13.15. Estes versículos descrevem, com algumas variações, a exigência de santificar (consagrar) todo primogênito (todo o que abre o útero) ao Senhor. Em Ex 13,14-16, se apresenta a razão dessa consagração: os filhos de Israel devem "regastar" (verbo $\lambda u \tau \rho o ́ \omega)$ seus primogênitos, humanos e animais, para fazer memória da páscoa, a noite da libertação do Egito. Naquela noite os primogênitos de Israel foram preservados da morte, enquanto os primogênitos do Egito, animais e humanos, foram mortos pelo anjo do Senhor (Ex 12,12-13.29). O sentido teológico de fundo é a ideia da pertença; se o povo já pertencia ao Senhor por haver sido libertado do Egito, os primogênitos the pertencem duplamente porque foram preservados da morte ${ }^{26}$.

Segundo Ex 13,2.12, todo primogênito deve ser santificado. O sentido de fundo, formulado com $\alpha \phi \alpha \iota \iota^{\prime} \omega$, é separar para, sacar a parte (v.12a); este conceito é destacado pelo verbo $\dot{\alpha} \gamma\llcorner\alpha \dot{\zeta} \zeta \omega$ que acrescenta a ideia de fazer santo, consagrar (vv.2a.12b). Em ambos os casos, o complemento no dativo se refere ao Senhor; no v.12 é assinalado explicitamente ( $\tau \hat{\omega}$ kvpí $\omega)$ enquanto que no v.2 se emprega o pronome da primeira pessoa do singular $(\mu \mathrm{o})$.

Os verbos $\dot{\alpha} \phi \alpha \iota \rho \epsilon ́ \omega$ e $\dot{\alpha} \gamma\llcorner\dot{\alpha} \zeta \omega$ não aparecem nos vv.13b.15b; em ambos os

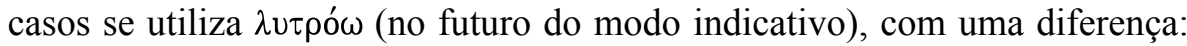
no v.13b, que é conjugado na segunda pessoa do singular ("tu resgatarás"); no v.15b se utiliza na primeira singular ("eu resgatarei"); além disso, o sujeito, no v.13b, é o fiel israelita, enquanto que no v.15b, é o Senhor.

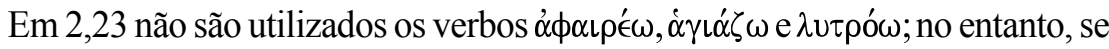
emprega $\kappa \alpha \lambda \lambda^{\prime} \omega^{27}$. Esta substituição parece importante para compreender o sentido

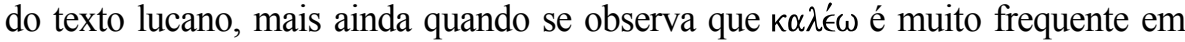

\footnotetext{
${ }^{25}$ Segundo H.L. STRACK; P. BILLERECK, Kommentar zuum Neuen Testament, II, 120, o resgate dos primogênitos foi instituído depois que os levitas foram designados para o serviço permanente no santuário e o resgate podia ser pago em qualquer lugar frente a qualquer sacerdote.

${ }^{26}$ T. STRAMARE, Sanctus Domino vocabitur (Lc. 2,23): il crocevia dei riti e la santità. Bibbia e Oriente 25 (1983), 25.

${ }^{27}$ J. ECKERT, K $\alpha \lambda^{\prime} \epsilon \omega$, In: H. Balz; G. Schneider (Eds.), Diccionario Exegético del Nuevo Testamento, I, Sígueme: Salamanca 1996, 2166-2167, esse verbo aparece em quase todos os escritos do NT. Em geral, se utiliza com genitivo no sentido de chamar alguém ou na voz passiva no sentido de ser chamado, chamar-se, pelo nome. Na obra lucana, $\kappa \alpha \lambda \lambda^{\prime} \omega$ é usado 59x (18x em At; $41 \mathrm{x}$ em Lc), entre as quais, $14 \mathrm{x}$ em Lc 1-2.
} 
Lc 1-2 ${ }^{28}$. Convém destacar também que a ideia de "santificação" não desaparece

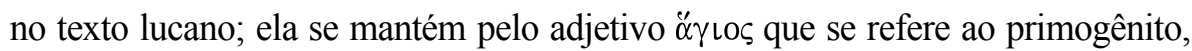
sujeito que sofre a ação de $\kappa \alpha \lambda \lambda^{\prime} \omega$ (na voz passiva). O complemento em dativo se refere "ao Senhor" ( $\tau \hat{\omega}$ Kupí̂ি) da mesma forma que em Ex 13,12.

Quando se compara Lc 2,23b.c com Ex 13.12.12.13b.15b se nota que

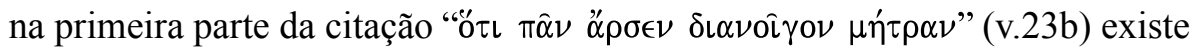
semelhança textual entre eles; neste caso, se se parte das hipóteses de que a LXX serviu de substrato, se poderia afirmar que o autor cristão não modificou substancialmente o texto citado.

No entanto, na segunda parte “" $\alpha$ ” observa um importante trabalho de redação. A omissão de $\dot{\alpha} \phi \alpha \iota \rho \hat{\epsilon} \omega, \dot{\alpha} \gamma\llcorner\dot{\alpha} \zeta \omega$,

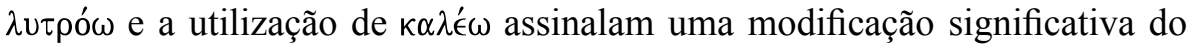
texto citado. Esta diferença não pode ser considerada uma simples casualidade. Na realidade, existe uma intenção cristológica associada a $1,35^{29}$.

A importância dessa alteração se faz mais evidente quando se observa que o v.23c corresponde ao centro do texto lucano em questão. Além disso, deve-se notar que associado ao verbo $\kappa \alpha \lambda \lambda^{\prime} \epsilon$ se mantém o dado da santificação (consagração) do primogênito, assinalada pelo adjetivo $\alpha$ $\operatorname{loc}^{30}$ e não mais pelo verbo $\dot{\alpha} \gamma\llcorner\alpha \dot{\zeta} \zeta \omega$, que foi omitido. Esta associação constitui, como já foi mencionado, o ponto central da inclusão, onde se expressa o dado teológico central: a santidade do menino apresentado no Templo.

Além disso, nos vv.22-24.39 a ideia do resgate do primogênito se perde totalmente. $\mathrm{O}$ evangelista não dá mais informações sobre a realização desse preceito da lei. Isto não ocorre somente pela ausência do verbo $\lambda \cup \tau \rho o ́ \omega$, senão também, porque não se faz referências ao pagamento exigido em

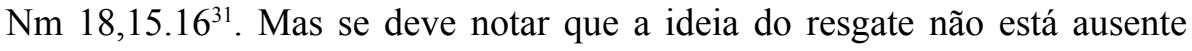

\footnotetext{
${ }^{28}$ Das $14 \mathrm{x}$ em que o verbo aparece em Lc $1-2,6 \mathrm{x}$ se referem a Jesus $(1,31.32 .35 ; 2.21(2 \mathrm{x}) .23)$; outras 6x a João (1,13.59.60.61.62.76); $1 \mathrm{x}$ a Isabel $(1,36)$ e $1 \mathrm{x}$ à cidade de Belém $(2,4)$.

${ }^{29}$ R. MEYNET, Il Vangelo secondo Luca, Bologna: Paideia, 2003, 113; M. MIYOSHI, "Jesu Darstellung oder Reinigung im Tempel unter Berucksichtigung von 'Nunc Dimittis' LK II, 22-38", 95.

${ }^{30}$ Segundo O. MAINVILLE, "Le Messianisme de Jesús. Le rapport annonce/accomplissement entre Lc 1,35 et Ac 2,33", BEThL 142, Leuven 1999, 324, o termo ä $\gamma$ lo é utilizado em Lc-At como título substantivado para referir-se a Cristo ressuscitado... "o Santo que irá nascer será chamado filho de Deus" (1,35).

${ }^{31}$ N. VISSER, “De veertig voldragen. Waarom Hanna trekken van Judit meekreeg” BenT 53 (1992), 166.
} 
em 2,25-38; ela reaparece na conclusão do relato da profetisa Ana (v.38), na qual se utiliza o substantivo $\lambda \dot{v} \tau \rho \omega \sigma \iota \varsigma^{32}$.

Note-se que a afirmação central da inclusão (vv.22-24.39) não recai sobre a purificação da mãe nem sobre o resgate do menino. Na realidade, o texto converge para a santidade do menino (v.23c). Esta centralidade estrutural indica a importância teológica e este dado poderia ser a pista principal para compreender a composição canônica de Lc 2,22-39.

\section{Conclusão}

Deve reconhecer que as prescrições sobre a purificação da parturiente (Lv 12,4.6.8) e sobre o resgate dos primogênitos (Ex 13,12-13) são o substrato veterotestamentário de 2,22-24. No entanto, como foi demonstrado, estes textos foram utilizados de forma livre ${ }^{33}$. Isto significa que o autor se permitiu interpretar os textos sagrados, reelaborando-os segundo suas intenções teológicas. É evidente que o objetivo do autor não é comentar trechos do AT, senão o de anunciar a Jesus, o Messias, à luz das Escrituras Veterotestamentárias. Para alcançar este objetivo, o autor desenvolve todo um trabalho hermenêutico sobre o qual fundamenta sua intenção de revelar aos leitores o dado central do Kerygma cristão.

Segundo esta pesquisa, é nessa perspectiva que deve-se compreender o conteúdo teológico dos relatos de Simeão (vv.25-35) e de Ana (vv.36-38). O redator final lucano teria inserido as duas composições no meio do texto preexistente (2,22-24.39) que, ao ser dividido, transforma-se numa inclusão inicial (vv.22-24) e final (v.39) para toda a perícope $(2,22-39)$ e, assim, explicar teológicamente o segmento central do texto preexistente (v.23c).

\footnotetext{
${ }^{32}$ M. MIYOSHI, Jesu Darstellung oder Reinigung im Tempel unter Berucksichtingung von 'Nunc Dimittis' Lk II,22-38, Annual of the Japanese Biblical Institute 4 (1978), 95.

${ }^{33}$ L. VENARD, Citations de l'Ancien Testament dans le Nouveau Testament, In: L. Pirot; A. Robert (Eds.), Dictionnaire della Bible Supplément, 2 (1934), 37-38; D.L. BOCK, Proclamation from Prophecy and Pattern. Lucan Old Testament Christology, Sheffield: Sheffield Academic, 1987, 39.
} 


\section{Referências Bibliográficas}

BAUER, W.; ARNDT, W. F.; GINGRICH, F. W.; DANKER, F. W., (Eds). A Greek-English Lexicon of the New Testament and Other Early Christian Literature, Chicago: Chicago University Press / London: Williams and Norgate, 1979.

BOCK, D.L. Proclamation from Prophecy and Pattern. Lucan Old Testament Christology, Sheffield: Sheffield Academic, 1987 (Journal for the Study of the New Testament Supplement Series 12).

BOVON, F. El Evangelio según san Lucas, I, Salamanca: Sígueme, 1995.

BROWN, R.E. El nacimiento del Mesías. Comentario a los relatos de la infancia, Madrid: Cristiandad, 1982.

BROWN, R.E.; DONFRIED, K.P.; FITZMYER, J.A.; REUMANN, J. (Eds.), María en el Nuevo Testamento, Salamanca: Sígueme, $2002^{4}$.

BULTMANN, R. The History of the Synoptic Tradition, Oxford: Blackwell, 1963.

COLERIDGE, M. Nueva lectura de la infancia de Jesús. La narrativa como cristología en Lucas 1-2, Córdoba: El Almendro, 2000.

CORTÉS, E. Los discursos de Adiós de Gn 49 a Jn 13-17. Pistas para la historia de un género literario en la antigua literatura judía, Barcelona: Herder, 1976.

CULPEPPER, R.A. The Gospel of Luke, In: L.E. KECK (Ed.), The New Interpreter's Bible, IX, Nashville: Abingdon Press, 1996.

ECKERT, J. “к $\alpha \lambda \lambda^{\prime} \omega$ ”, In: H. Balz; G. Schneider (Eds.), Diccionario Exegético del Nuevo Testamento, I, Sígueme: Salamanca 1996, 2166-2167,

GARCÍA PÉREZ J.M.; HERRANZ MARCO, M. La infancia de Jesús según Lucas, Madrid: Ediciones Encuentro, 2000. (Studia Semitica Novi Testamenti, VI).

HARTLEY, J.E. Leviticus, Word Biblical Commentary 4, Dallas: Word Books, 1992. 
LAGRANGE, M.-J. Évangile selon saint Luc, Paris: Lecoffre, 1921.

LAURENTIN, R. I vangeli dell'infanzia di Cristo. La verità del natale al di là dei miti, Milano: Paoline, 1986.

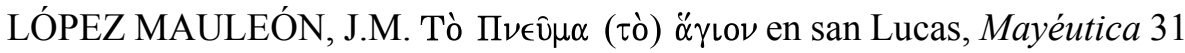
(2005) 273-370.

MAINVILLE, O. Le Messianisme de Jesús. Le rapport annonce/ accomplissement entre Lc 1,35 et Ac 2,33, Bibliotheca Ephemeridum Theologicarum Lovaniensium 142 (1999) 313-327.

MEYNET, R. Il Vangelo secondo Luca, Bologna: Paideia, 2003.

MIYOSHI, M. Jesu Darstellung oder Reinigung im Tempel unter Berucksichtingung von 'Nunc Dimittis' Lk II,22-38, Annual of the Japanese Biblical Institute 4 (1978) 85-115.

MUÑOZ IGLESIAS, S. Los Evangelios de la infancia, I, III, Madrid: Editorial Católica, 1990², 1987 (Biblioteca de Autores Cristianos).

NEF ULlOA, B. A., A Apresentação de Jesus no Templo. (Lc 2,22-39). O testemunho profético de Simeão e Ana como icone da história da Salvação". São Paulo: Paulinas 2012 (Coleção Exegese).

NOTH, M. Levítico, Brescia: Paideia, 1989.

PÉREZ FERNÁNDEZ, M. Tradiciones Mesiánicas en el Targum Palestinense, Valencia: Artes Gráficas Soler, 1981.

RADL, W., Der Ursprung Jesu. Traditionsgeschichtliche Untersuchungen zu Lukas 1-2, Freiburg: Herder, 1996.

SIMÓN MUÑOZ, A. El Mesías y la hija de Sión. Teologia de la redención en Lc 2,29-35, Madrid: Ciudad Nueva, 1994. (Studia Semitica Novi Testamenti, III).

SCHÜRMANN, H. Il vangelo di Luca, I, Brescia: Paideia, 1983.

STRACK, H.L. - BILLERECK, P. Kommentar zum Neuen Testament aus Talmud und Midrasch, I, München: Beck, 1924.

STRAMARE, T. Sanctus Domino vocabitur (Lc. 2,23): il crocevia dei riti e la santità. Bibbia e Oriente 25 (1983) 21-34. 
THOMAS, K.J. Torah Citations in the Synoptics. New Testament Studies 24 (1977) 85-96.

VALENTINI, A. La rivelazione di Gesù dodicenne al Tempio (Lc 2,41-52). Estudios Bíblicos 50 (1992) 261-304.

VENARD, L. Citations de l'Ancien Testament dans le Nouveau Testament, In: L. Pirot; A. Robert (Eds.), Dictionnaire della Bible Supplément, 2 (1934) 23-51. Paris: Librairie Letouzey et Ané.

VISSER, N. De veertig voldragen. Waarom Hanna trekken van Judit meekreeg. Benedictijns Tijdschrift 53 (1992) 139-154.

Boris Agustín Nef Ulloa

Prof. Dr. do Departamento de Teologia Fundamental da PUC-SP Coordenador do Curso de Teologia da PUCSP - Campus Ipiranga Membro do Programa de Estudos Pós-graduados em Teologia da PUC-SP Brasil E-mails: baulloa@pucsp.brou banefulloa@gmail.com

Recebido em 01/06/13 Aprovado em 19/10/13 